Resumo

\title{
Análise do desempenho do salto vertical de atletas de pentatlo militar
}

Andreson Santos Bezerra Bsci, Miguel Charbel BSci

Introdução: A Pista de Pentatlo Militar é composta por diversos obstáculos que requer explosão e força dos membros inferiores dos atletas. Sabe-se das características fisiológicas que proporcionam um bom desempenho nos saltos verticais, porém a literatura é carente na associação dessas características com o bom desempenho na PPM.

Objetivo: O presente estudo investigou a influência da ação dos membros superiores e do índice elástico na capacidade de execução de saltos verticais da equipe de Pentatlo Militar do Brasil.

Métodos: Participaram do estudo quatro atletas de Pentatlo Militar da equipe do Brasil, saudáveis e experientes, adaptadas ao treinamento pliométrico. Foram executados três diferentes tipos de saltos, squat jump, Salto com contramovimento e Abalakov. Foi possível observar a contribuição dos braços, índice elástico e contribuição elástica das atletas. Cada indivíduo realizou um total de seis séries de salto, sendo dois para cada tipo, realizados de maneira randômica, sem a possibilidade de realizar o mesmo tipo de salto em duas séries consecutivas. Foi respeitado o intervalo de 2 minutos entre cada série de saltos, em cada um dos testes a maior altura atingida foi atribuída para aquela modalidade de salto. Para observar a distribuição de todos os saltos, foi utilizado o teste de Shapiro-Wilk e pela presença de amostras não paramétricas, dados ordinais, com um número superior de duas amostras foi elegido o teste KruskalWallis. Foi realizado o teste de Spearman para observar a diferença entre os dados de cada tipo de salto e entre todos os dados de uma mesma atleta. Os melhores tempos das atletas na PPM foram adquiridos com a comissão técnica da equipe de Pentatlo do Brasil.

Resultados: Os saltos utilizando os membros superiores e o ciclo excênticoconcêntrico alcançaram os maiores saltos entre os três diferentes citados.

Conclusão: Verificou-se a influência dos braços e dos elementos elásticos dos músculos para a realização de um melhor salto vertical, consolidando a importância dos treinamentos pliométricos para o ganho de força e explosão. Porém, não foi possível estabelecer uma relação entre esses elementos e um melhor desempenho na PPM. 